Jahangirnagar University J. Biol. Sci. 8(1): 83-86, 2019 (June)

\title{
-Short communication
}

\section{Effect of temperature and relative humidity on the population dynamics of brinjal and tomato infesting whitefly, Bemisia tabaci}

\author{
M. M. H. Khan* \\ Department of Entomology, Patuakhali Science and Technology University, \\ Dumki, Patuakhali-8602, Bangladesh
}

Whiteflies develop rapidly in warm weather, and population can build up quickly in situations where natural enemies are destroyed and weather is favorable. Heavy and prolonged periods of rain can substantially reduce population of whiteflies (Rafiq et al., 2008). Pest abundance and their distribution also changes with abiotic factors and therefore meteorological parameters play a pivotal role in the biology of many pests. Temperature is the most crucial abiotic factors influencing the rate of growth and development of insects. However, relative humidity and temperature are the chief weather parameters that largely direct the activity of a given species of insect. The interaction between pest activity and abiotic factors helps in deriving at predictive models that aids in forecast of pest incidence. Considering above facts the present study was aimed to know the effect of temperature and relative humidity on the population dynamics of the brinjal and tomato infesting whitefly, Bemisia tabaci.

Experiments were conducted in the experimental farm of Patuakhali Science and Technology University (PSTU) during November 2013 to April 2014. Seeds of brinjal and tomato were collected from Bangladesh Agricultural Research Institute, Gazipur. The partially germinated seeds of brinjal and tomato were grown individually in $12 \mathrm{~cm}$ diameter plastic pots. Seedlings of 4 leaf stage were used in the experiment and a total of 30 plants taking 15 from brinjal and 15 from tomato were used as study materials. The observation of whitefly was recorded at weekly intervals during morning hours between 6:30 AM and 8:30 AM. The number of whiteflies (nymphs and adults) was recorded from five leaves (two from the upper and middle canopy, one from lower canopy) of five randomly selected plants. The whitefly population was recorded on the basis of their numbers per plant. The weekly meteorological data on temperature and relative humidity were recorded during the experimental period.

Relationship between the number of whitefly with temperature and relative humidity: A strong positive and linear relationship $(r=0.972)$ was observed between population of Bemisia tabaci and average temperature in brinjal host (Fig. 1). The contribution of regression $\left(\mathrm{R}^{2}=0.945\right)$ was $95 \%$. However, in tomato, a strong negative and linear relationship $(\mathrm{r}=-0.713)$ was observed between number of whitefly population

\footnotetext{
*Author. E-mail: mohasin1965@pstu.ac.bd
} 
and average temperature (Fig. 1). This suggests that the development of whitefly population on tomato dependent on temperature.

A positive and linear relationship $(\mathrm{r}=0.619)$ was observed between population of Bemisia tabaci and average relative humidity in brinjal host (Fig. 1). The relationship suggested that the number of whitefly population was dependent on humidity. The contribution of regression $\left(\mathrm{R}^{2}=0.383\right)$ was $38 \%$. In case of tomato, a negative and linear relationship $(\mathrm{r}=-0.045)$ was observed between number of whitefly population and average relative humidity (Fig. 1). It suggests that the number of whitefly population was less dependent on humidity. The contribution of regression $\left(\mathrm{R}^{2}=0.045\right.$ ) was $05 \%$ (Fig. $1)$.
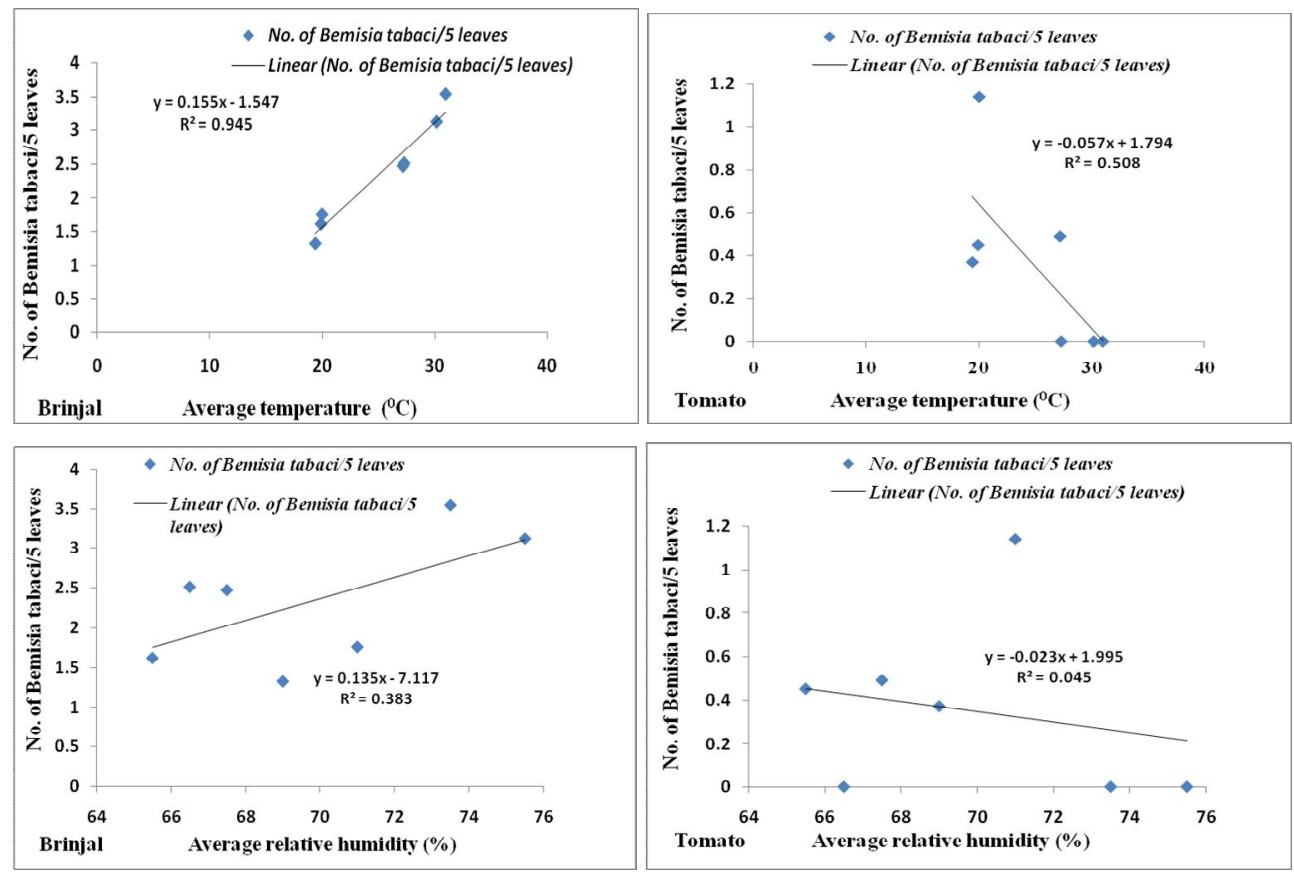

Fig. 1. Relationship between population of Bemisia tabaci in brinjal and tomato with average temperature (above left $\&$ right) and average relative humidity (below left $\&$ right)

Relationship between infestation by whitefly with average temperature and relative humidity: A strong positive and linear relationship $(\mathrm{r}=0.735)$ was observed between $\%$ infested plant by whitefly and average temperature in brinjal host (Fig. 2). The relationship suggested that the percentage of plant infested by whitefly was dependent on temperature. The contribution of regression $\left(\mathrm{R}^{2}=0.540\right)$ was $54 \%$. In case of tomato, a negative and linear relationship $(r=-0.615)$ was observed between number of whitefly and average temperature (Fig. 2). This suggests that the percentage of plant infested by whitefly was less dependent on temperature. The contribution of regression $\left(R^{2}=0.378\right)$ was $38 \%$ (Fig. 2). 


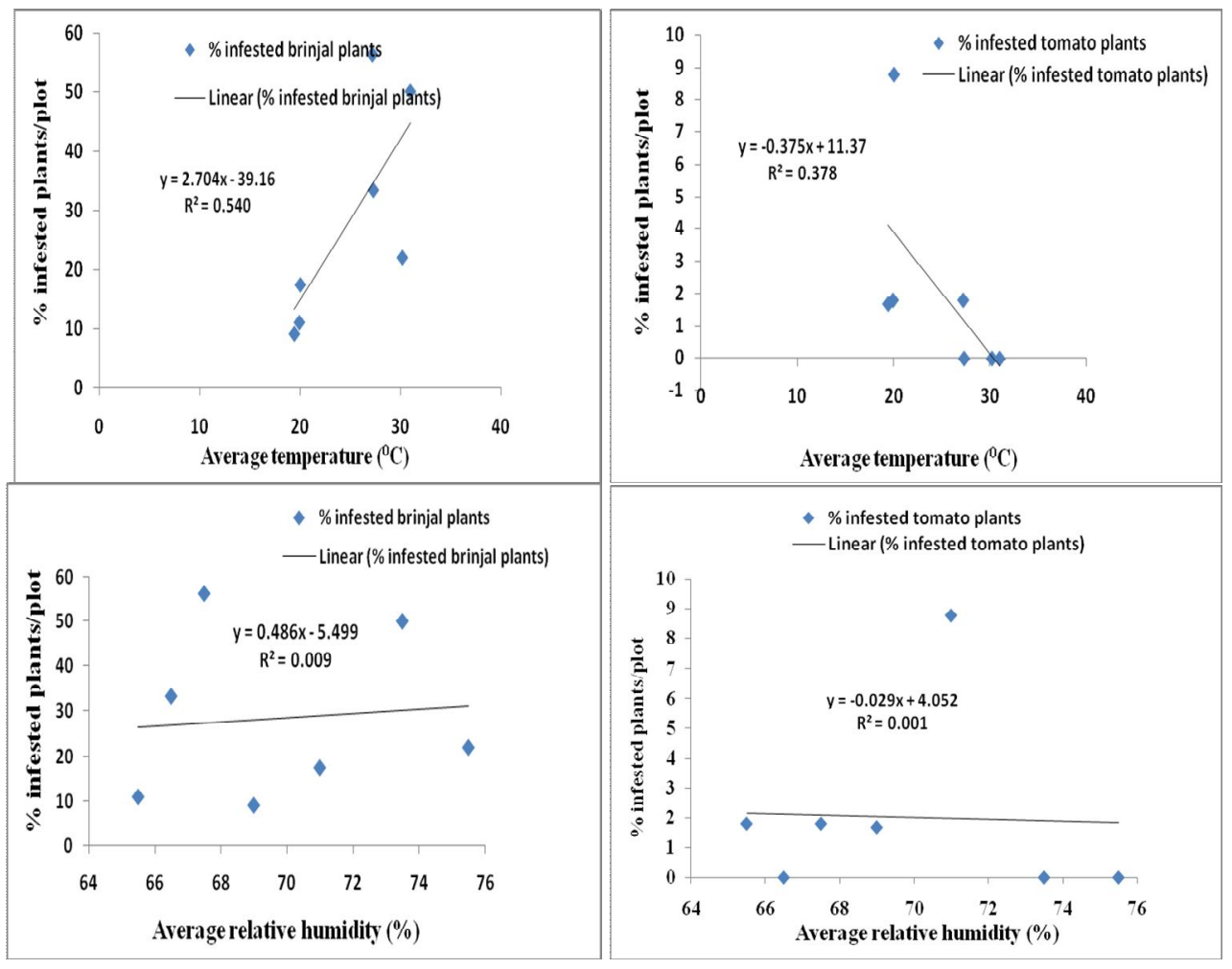

Fig. 2. Relationship between infestation of brinjal and tomato with average temperature (above left $\&$ right) and average relative humidity (below left $\&$ right)

The contribution of regression $\left(\mathrm{R}^{2}=0.009\right)$ was $0.9 \%$. In case of tomato, a negative and linear relationship $(\mathrm{r}=-0.032)$ was observed between $\%$ infested plant by whitefly and average relative humidity (Fig. 2). This suggests that the percentage of plant infested by whitefly was very less dependent on humidity. The contribution of regression $\left(\mathrm{R}^{2}=\right.$ 0.001 ) was $0.1 \%$ (Fig. 2).

The population of Bemisia tabaci had a significant impact when the temperature changed. High temperature resulted in a decrease in the pest population. This is possibly due to the fact that the immature stages of $B$. tabaci were desiccated when the temperature was high. Gerling et al. (1986) stated that extreme relative humidity, both high and low, were unfavorable conditions for the survival of immature stages of B. tabaci. They also mentioned that the major factors influencing the population density of $B$. tabaci were spatio-temporal (factors influence the population such as natural enemies, climatic and habitats) variations in the area. Anjali et al. (2012) conducted a study to observe the effect of abiotic factors on the seasonal incidence of major insect pests on brinjal crop during rabi 2009 and noted that the leaf hopper (Amrasca biguttula biguttula) population 
was minimum during March (12th $\mathrm{SW}$ ) and the white fly (B. tabaci) population was maximum during January. Both these insects showed significant negative correlation with both maximum and minimum temperature and wind speed while a positive correlation was revealed with mean relative humidity and total rainfall. Echlkraut \& Cardona (1989) observed that dry conditions were more favourable for $B$. tabaci than high precipitation. Salinas \& Sumalde (1994) reported that the presence of whitefly was year round and showed negative response to high temperature and rainfall. Horowitz et al. (1984) and Horowitz (1986) also reported that the atmospheric humidity, temperature and rainfall influence the population dynamics of whitefly.

From the findings of the present study it can be concluded that a strong positive and linear relationship was observed between population of $B$. tabaci and infestation of brinjal plants by whitefly with average temperature and average relative humidity, while a negative and linear relationship was noted between same parameters in tomato.

\section{REFERENCES}

Anjali, M., Singh, N. P., Mahesh, M. and Singh, S. 2012. Seasonal incidence and effect of abiotic factors on population dynamics of major insect pests on brinjal crops. J. Environ. Res. Develop. 7 (1A): 431-435.

Echlkraut, K. and Cardona, C. 1989. Biology, mass rearing and ecological aspects of the whitefly, Bemisia tabaci (Gennadius) (Homoptera: Aleyrodidae) as a pest of bean. Turrialba. 39: 55-62.

Gerling, D., Horowitz, A. R. and Baumgartner, J. 1986. Autecology of Bemisia tabaci. Agric. Ecosyst. Environ. 17: 5-19.

Horowitz, A.R., 1986. Population dynamics of Bemisia tabaci (Gennadius):with special emphasis on cotton fields. Agric. Ecosyst.Environ. 17(1-2): 37-47.

Horowitz, A.R., Podoler, H., Gerling, D. 1984. Life table analysis of the tobaco whitefly Bemisia tabaci (Gennadius) in cotton fields in Israel. Acta Oecol. 5(3): 221-233.

Rafiq, M., Ghaffar, A. and Arshad. M. 2008. Population dynamics of whitefly (Bemisia tabaci) on cultivated crop gosts and their role in regulating its carry-over to cotton. Int. J. Agric. Biol. 10(5): 577-580.

Salinas, M. D. and Sumalde, A. C. 1994. Life history, seasonal abundance and host range of the wooly whitefly, Aleurocanthus floccossus (Maskell). Pest management council of the Philippines, Increased, College, Laguna (Philippines). Integrated pest management: Learning from experience, College, Laguna (Philippines), PMCP. 29p. 